\title{
FATIGUE REPAIRING CRAFTSMANSHIP OF DECK-TO-VERTICAL STIFFENER WELD IN THE STEEL BRIDGE DECK
}

\author{
Yi-xun Wang ${ }^{1}$, Bo-hai Ji ${ }^{1, *}$, Zhong-qiu Fu ${ }^{1}$ and Yue Yao ${ }^{1}$ \\ ${ }^{1}$ School of Civil and Transportation Engineering, Hohai University, Nanjing 210098, China \\ * (Corresponding author: E-mail: bhji@hhu.edu.cn)
}

\section{A B S T RA C T}

Experiments and FE analysis were conducted on the fatigue repairing techniques of deck-to-vertical stiffener weld in the steel bridge deck. The steel bridge deck was modeled to analyze cracking reason of deck-to-vertical stiffener weld. The fatigue repairing experiment was carried out on three repairing techniques. The fatigue life and stress distribution of the deck-to-vertical stiffener weld were analyzed and repairing effects were compared. Repairing craftsmanship with different parameters was modeled to study change of stress distribution. Besides, influence of welding residual stress, stop-hole and CFRP reinforcement on fatigue repairing was discussed. The results showed that cracks of welding end on the deck were induced by out of plane deformation while those on the vertical stiffener were caused by combined out-of-plane and inplane deformation, which was more prone to cracking. Residual tensile stress reached yield strength of steel after rewelding, thus hammering and polishing after re-welding could improve fatigue life of the weld. The re-welding techniques had more favorable repairing effects than stop-hole and CFRP reinforcement

\section{A R T I C L E H I S T O R Y}

$\begin{array}{ll}\text { Received: } & \text { 22 April } 2018 \\ \text { Revised: } & \text { 9 September } 2018 \\ \text { Accepted: } & \text { 28 October } 2018\end{array}$

\section{K E Y W O R D S}

Steel bridge deck;

Vertical stiffener;

Fatigue crack;

Cracking reason;

Repairing techniques

Copyright $\odot 2019$ by The Hong Kong Institute of Steel Construction. All rights reserved.

\section{Introduction}

The orthotropic steel bridge deck is widely applied in long-span steel bridges in the globe for its light self-weight, high strength and convenient construction [1]. The orthotropic steel bridge deck is prone to fatigue damage under daily traffic loads which reduce its service life [2-3]. The deck-to-vertical stiffener weld is one of the fatigue details most likely to be cracking in the steel bridge. An investigation by the Japanese Steel Structure Committee of Civil Society was conducted on the steel bridge deck of Hanshin Expressway and Capital Expressway in 2007. The results indicated that a large number of cracks was detected in the deck-to-vertical stiffener weld [4]. Therefore, it is necessary to study on the fatigue repairing techniques on the deck-to-vertical stiffener weld for its life extension. At present, repairing techniques commonly applied on the steel bridge deck include re-welding, drilling stop-hole, CFRP reinforcement, etc. [5-7]. The crack propagation is slowed down by removing crack tips or increasing local bearing capacity.

A lot of studies have been conducted on fatigue repairing techniques of steel bridge deck by scholars worldwide. Aljabar, NJ [8] researched on CFRP reinforcement on the cracks in steel bridge deck under combination of tensile and shearing stress and a hybrid modal parameter was proposed to estimate fatigue life of the steel bridge deck with initial cracks. J Crain [9] established finite element models of stop-hole to investigate its enhancement for fatigue performance of steel bridge deck and Figured out a method to improve crack arresting effects. To study the bending performance of steel girder by CFRP reinforcement, Yail J. Kim[10] designed 6 steel girders with different parameters for experiment and found that the fatigue response of CFRP-steel interface was bilinear and determined by stress ranges and cycles. Hyun-Chan Park[11] conducted a re-welding experiment on the deck welds and the result indicated that re-welding could effectively improve fatigue performance of welding details. A lot of current research achievements have been applied to fatigue repairing in real bridges, which rarely involves in cracking of deck-tovertical stiffener weld, though. A series of repairing parameters have been proposed for deck-U rib welds, weld scallop of diaphragm and other typical fatigue details, whereas these repairing parameters are supposed not to be applied directly to the deck-to-vertical stiffener weld since fatigue performance varies a lot in different fatigue details.

Therefore, experiments and FE analysis were carried out on the fatigue repairing techniques of deck-to-vertical stiffener weld in steel bridge deck. The cracking reason of deck-to-vertical stiffener weld was analyzed and improvement of fatigue performance by different repairing craftsmanship was verified by fatigue experiment. As various influence could not be included in the experiment, parameter analysis was carried out by FE analysis. Advice for different fatigue repairing techniques was proposed and reference was provided for fatigue repairing in steel bridge deck.

\section{Stress characteristics of deck-to-vertical stiffener weld} 2.1. The finite element model

The position and structure of deck-to-vertical stiffener weld in steel bridges are depicted in Fig. 1. The crossing of the vertical stiffener and deck by welds results in great stress concentration and the complex welding workmanship renders great residual stress on the heat affected zone (HAZ), making it one of the most common crack initiations under the cyclic vehicle loads. The crack propagation detected in the real bridge is usually divided into two types. Type 1: the crack initiates from the welding end on the deck and develops into semicircles around the weld toe, then propagates on both sides of the deck along the longitudinal direction. Type 2: the crack initiates from the welding end on the vertical stiffener and develops along the weld toe or propagates through the weld and then onto the deck. Part of steel deck from a certain real bridge was modeled by ABAQUS to study the cracking reason of deck-to-vertical stiffener weld. The stress characteristics of welding end under the vehicle loads were also analyzed.

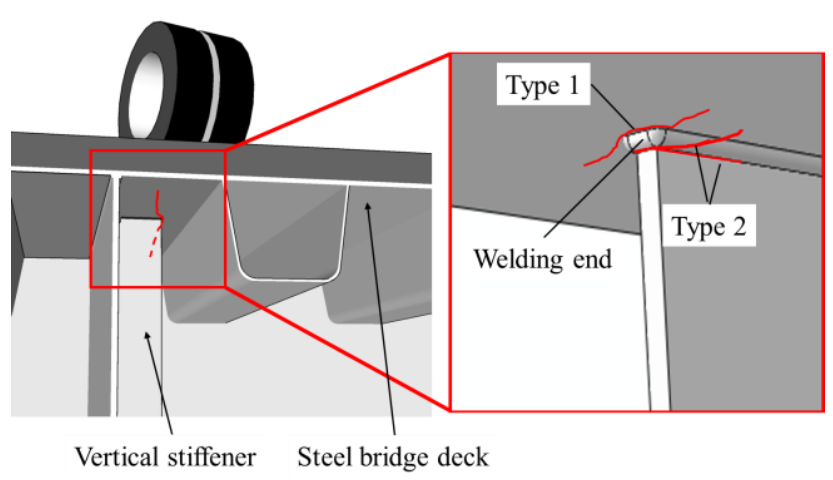

Fig. 1 The vertical stiffener in the steel bridge

The finite element model including $6 \mathrm{U}$ ribs transverse to the bridge and 4 diaphragms longitudinal to the bridge was established according to a recent report in Japan [12]. Based on the dimensions of components in the real bridge, the thickness of deck and its pavement was set as $12 \mathrm{~mm}$ and $80 \mathrm{~mm}$ respectively. The section dimension of $U$ rib was $320 \mathrm{~mm} \times 240 \mathrm{~mm} \times 6 \mathrm{~mm}$ and vertical stiffener was $150 \mathrm{~mm} \times 700 \mathrm{~mm}$. The web was $14 \mathrm{~mm}$ in thickness and the radius of weld scallop connecting the vertical stiffener, web and deck was $35 \mathrm{~mm}$. The specific dimensions were illustrated in Fig. 2. It was assumed all components in the steel deck worked in linear elasticity during the periods of vehicle loads. The elasticity modulus of steel was $2.06 \times 10^{5} \mathrm{MPa}$. The elasticity modulus of pavement was 1000MPa considering distinct change of elasticity modulus with 
the temperature, irrespective of the interface slippage between the deck and pavement [13]. All degrees of freedom at the diaphragm and three translational degrees of freedom around the model were restrained considering the constraints of the model in real bridge as a whole [14].

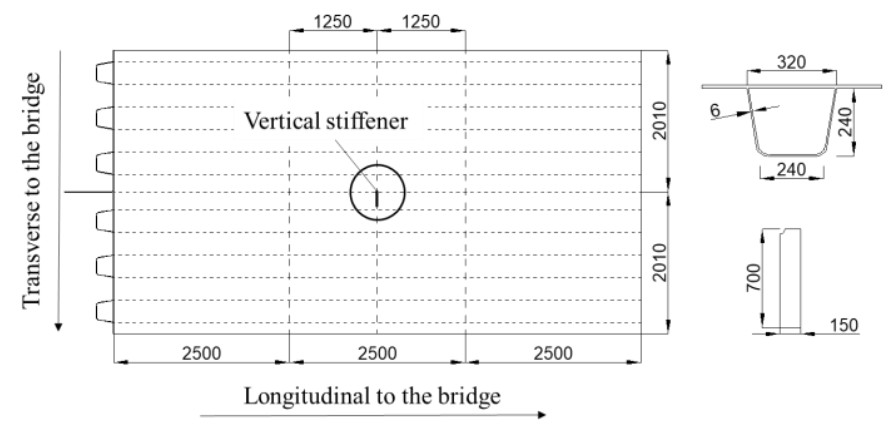

Fig. 2 The geometric dimension of the steel deck model

The huge difference in dimension of local details and model as a whole made mesh refinement difficult, thus the submodel method was commonly applied to build the model and improve computing efficiency. To establish the steel bridge deck with crossing longitudinal and transverse ribs which were sophisticated in geometric dimensions, deck-to-vertical stiffener weld was modeled by the submodel method. Both C3D8R element and C3D10 elements were applied for the base model and its submodel. The base model was meshed by hex elements with dimension of $20 \mathrm{~mm}$. The submodel was meshed by hex elements with dimension of $20 \mathrm{~mm}$ and refined on its welding region by hex elements with dimension of $1 \mathrm{~mm}$. Five different mesh sizes were applied to verify the accuracy of FE analysis of the submodel. The hex element which owned a size of $1 \mathrm{~mm}, 2 \mathrm{~mm}, 3 \mathrm{~mm}, 4 \mathrm{~mm}$ and $5 \mathrm{~mm}$ was calculated separately. It could be observed that the greatest stress difference was between the mesh size of $3 \mathrm{~mm}$ and $1 \mathrm{~mm}$, which was only $3.0 \%$. The stress curves showed a convergent solution for FE analysis with different mesh sizes. Therefore, the mesh size of $1 \mathrm{~mm}$ was applied to the FE model for calculating accuracy and efficiency. The tet element was applied to transit mesh from the refinement region to coarse region. The refinement of the submodel was shown in Fig. 3.

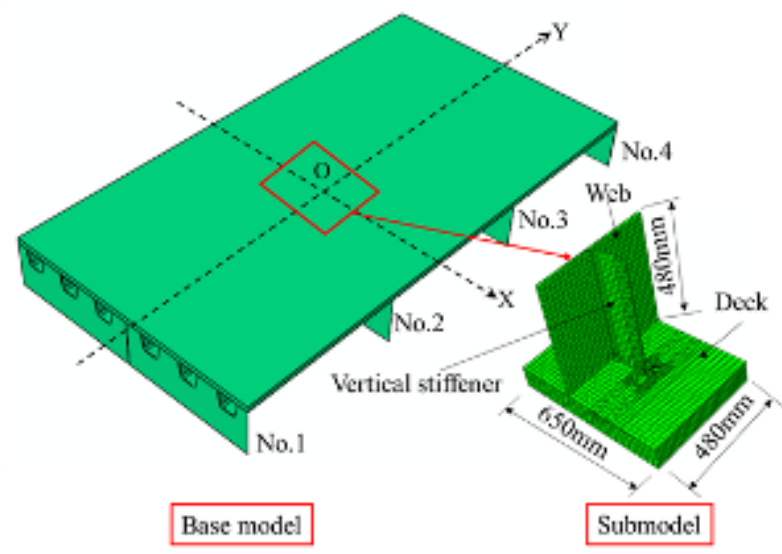

Fig. 3 The base model and submodel

A wheel load was picked up from the standard fatigue vehicle in the specification [15]. The wheel contact area was $600 \mathrm{~mm} \times 200 \mathrm{~mm}$ and the wheel force was $60 \mathrm{kN}$. The DLOAD subroutine was compiled based on FORTRAN to apply wheel load on the steel deck. The origin of coordinates was set on the welding end of deck-to-vertical stiffener weld, which was shown in Fig. 4. The transverse subload consisted of 15 static load cases with a loading space of $50 \mathrm{~mm}$ between case $5-9$ and $100 \mathrm{~mm}$ between the rest of cases. The wheel load ran from the diaphragm No.2 to No. 3 and longitudinal subload consisted of 25 static load cases with a loading space of $100 \mathrm{~mm}$.

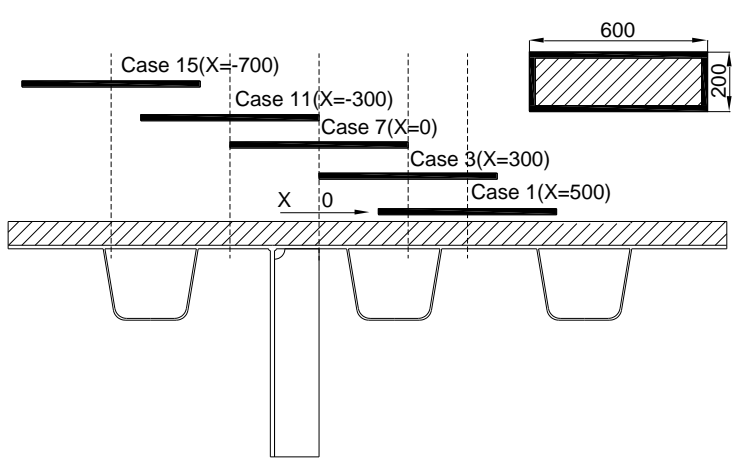

Fig. 4 The loading conditions

The premise to apply the submodel method was to ensure the boundary of the submodel was far enough from the stress concentration region, thus the stress on the boundary of the submodel should agree well with the identical position on the base model. By comparison of several trails with different submodel dimensions, the stress curves on the boundary of the submodel were proved to be consistent with those of the base model if the submodel's dimension was equal or greater than that in Fig. 3. Therefore, the following submodel analysis was based on this dimension.

\subsection{Stress analysis under the wheel load}

The cracks usually initiated at the welding end of the deck-to-vertical stiffener weld, thus the normal stress history of welding end on the deck and stiffener was obtained respectively and shown in Fig. 5.
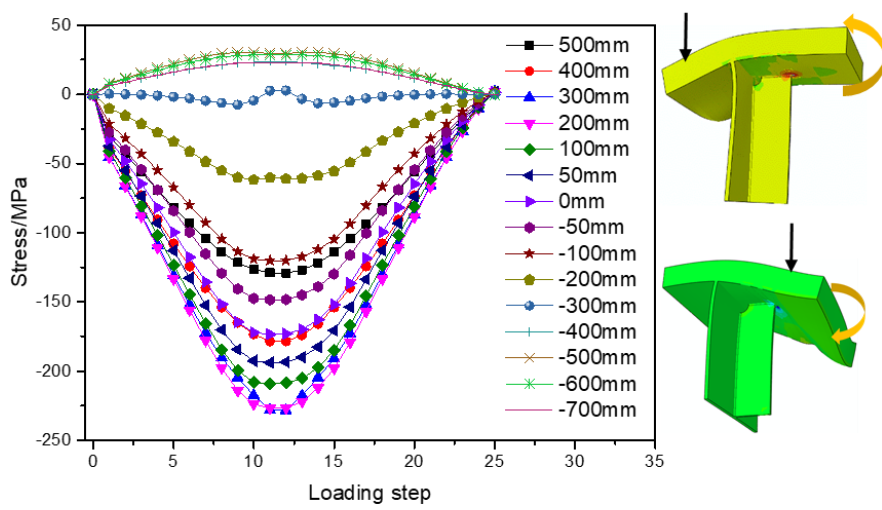

(a) Welding end on the deck

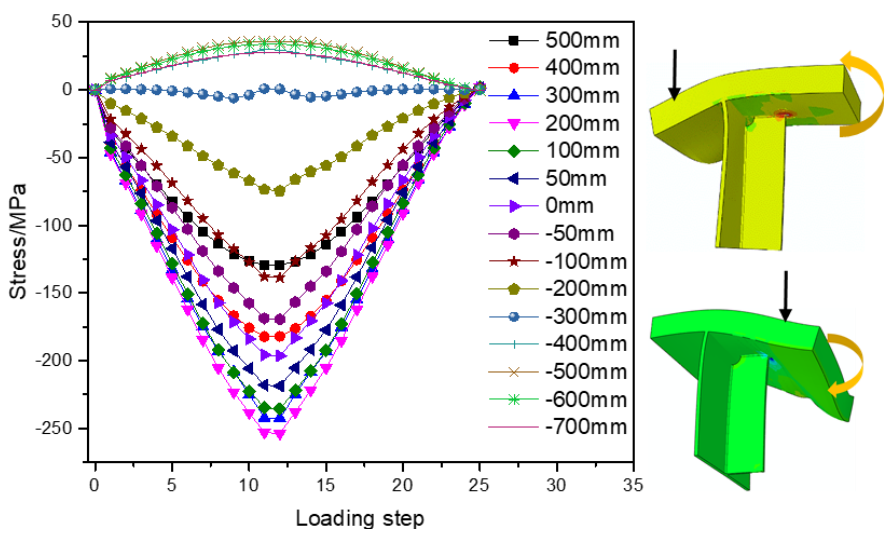

(b) Welding end on the stiffener

Fig. 5 Stress history under vehicle loading

As shown in Fig. 5, when the wheel load was applied on the left of the web, i.e., $\mathrm{X} \leq-300 \mathrm{~mm}$, tensile-compressive stress cycles or complete tensile stress cycles were observed on the welding end. Assuming the web as a pivot, the wheel load on the left of the web rendered the downward compressive deformation of the deck on the left web, driving the upward warping of the deck on the right web. Therefore, it caused tensile stress on the welding end connecting the deck and vertical stiffener, which was in the analogy of the 
"seesaw" action to some extent. When the wheel load was applied on the right of the web, i.e., $X \geq-300 \mathrm{~mm}$, complete compressive stress cycles were observed on the welding end. It could be deemed that the small fraction of the deck above the web had a larger stiffness because of the web support. Taking it as the fixed end, the wheel load applied on the right of the web rendered the constant compressive deformation of the deck on the right web, causing the compressive stress on the welding end connecting the deck and vertical stiffener. Generally speaking, the tensile-compressive stress cycles or complete tensile stress cycles, which were generated by wheel load applied on the left of the web, gave rise to the fatigue cracking on the deck-to-vertical stiffener weld. As the wheel load applied on the right web caused complete compressive stress cycles, it had a negligible influence on the cracking of this detail.

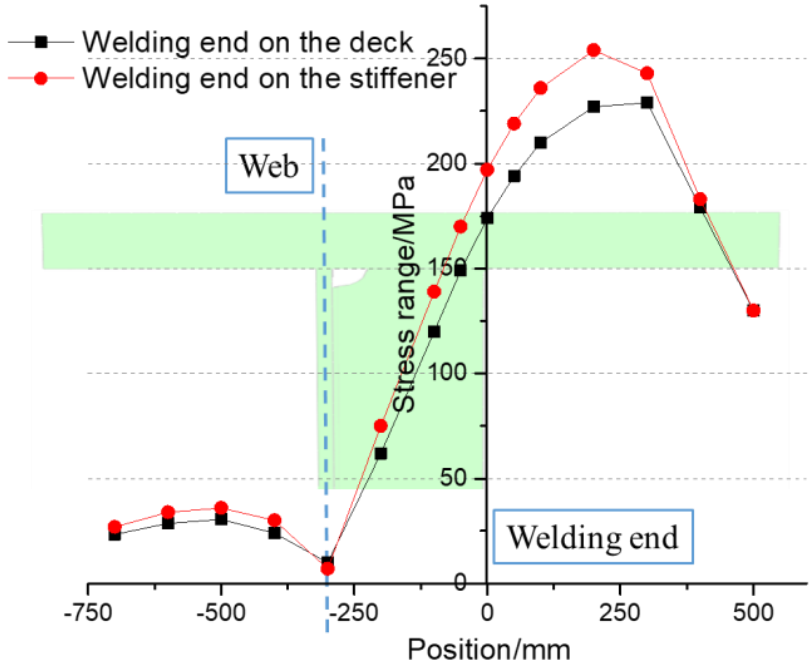

Fig. 6 Stress range

The rainflow method [15] was applied to count the stress history and obtain the stress ranges on the welding end of deck-to-vertical stiffener weld respectively. The minor stress ranges were neglected if several ranges were generated under the wheel load. The stress ranges under different transverse positions were illustrated in Fig. 6. Taking the welding end as the origin of coordinates, the tensile stress ranges on the left of web $(\leq-300 \mathrm{~mm})$ and compressive stress ranges on the right of web $(>-300 \mathrm{~mm})$ both increased first and then declined with the increment of distance from the welding end. Assume the web as a pivot. When wheel load was applied on the left of the web, the farther the wheel load was from the pivot, the longer the arm of force was, thus the greater the tensile stress range on the welding end would be. While a certain distance between the wheel load and web was reached, the effect of wheel load was weakened because of the stiffness by the neighboring $U$ ribs on the left. Therefore, as the distance increased, the tensile stress ranges of the welding end declined. Assume the small fraction of deck above the web as the fixed end. When wheel load was applied on the right of the web, the farther the wheel load was from the fixed end, the longer the arm of force was, thus the greater the compressive stress on the welding end would be. While a certain distance between the wheel load and web was reached, the effect of wheel load was weakened because of the stiffness by the neighboring $\mathrm{U}$ ribs on the right. Therefore, as the distance increased, the compressive stress ranges of the welding end declined. Generally speaking, the stress range of welding end on the vertical stiffener was greater than that on the deck, thus welding end on the vertical stiffener was more prone to crack with identical material and welding craftsmanship.

\subsection{Analysis of the cracking reason}

The results of stress ranges showed that the transverse position of wheel load on the $-500 \mathrm{~mm}$ was the most unfavorable working conditions for the tensile range, and $200 \mathrm{~mm}$ was the most unfavorable working conditions for the compressive range. For the welding end on the deck, the membrane stress, bending stress and normal stress of the cracking section when the wheel load was applied on the $-500 \mathrm{~mm}$ and $200 \mathrm{~mm}$ in transverse and the 13th static cases(the most unfavorable working conditions longitudinal to the bridge) in longitudinal were depicted in Fig. 7. The bending stress and membrane stress were extracted by Stress Linearization to judge the deformation features of this detail. The definition of membrane stress is the average normal stress across the thickness of a plate or shell. The bending stress refers to stresses which are linearly distributed across the thickness.

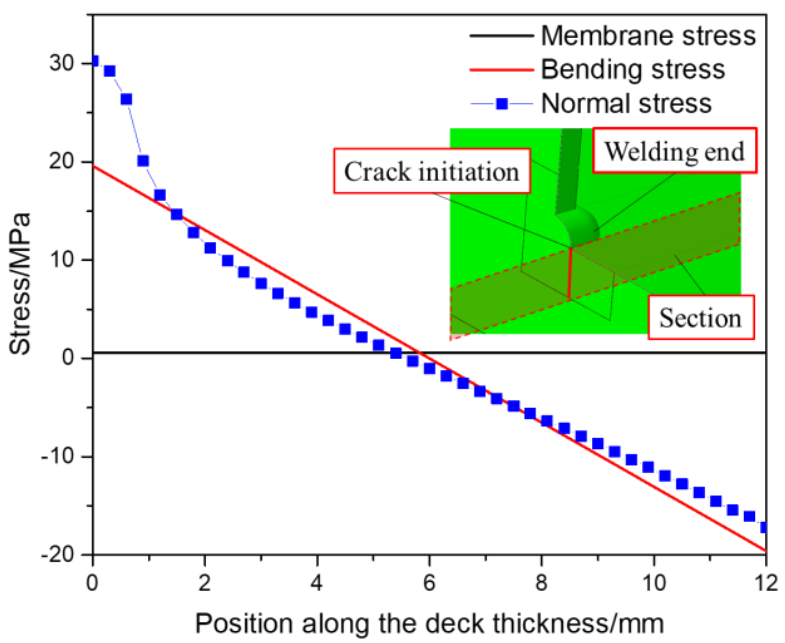

(a) $-500 \mathrm{~mm}$

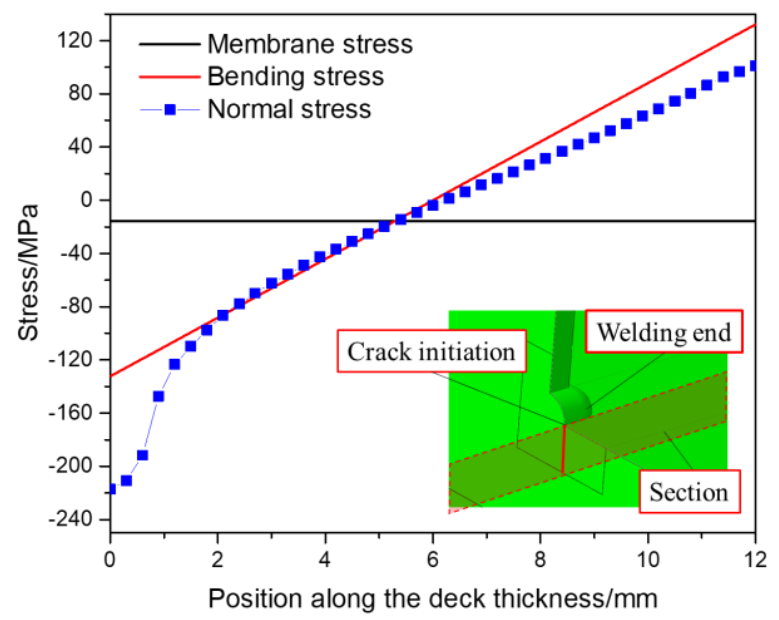

(b) $200 \mathrm{~mm}$

Fig. 7 Stress of welding end on the deck

As seen in Fig. 7, for wheel load on the $-500 \mathrm{~mm}$ in transverse, bending stress of the cracking section was $19.6 \mathrm{MPa}$, while the membrane stress was only equal to $3 \%$ of the bending stress, namely $0.6 \mathrm{MPa}$. It indicated that the fatigue cracking in this detail mainly resulted from the bending stress induced by out of plane deformation and membrane stress had a negligible influence on the cracking. Meanwhile, the nonlinear stress caused by geometric structure increased the normal stress by $33.3 \%$. Similarly, for wheel load on the $200 \mathrm{~mm}$ in transverse, the bending stress of the cracking section was $-132.4 \mathrm{MPa}$, while the membrane stress was only equal to $11.8 \%$ of the bending stress, namely 15.6MPa. Meanwhile, the nonlinear stress caused by geometric structure increased the normal stress by $32.3 \%$. Therefore, the cracking Type 1 of the deck-to-vertical stiffener weld, i.e., the crack initiated from the welding end on the deck, was caused by great out of plane deformation under the wheel load.

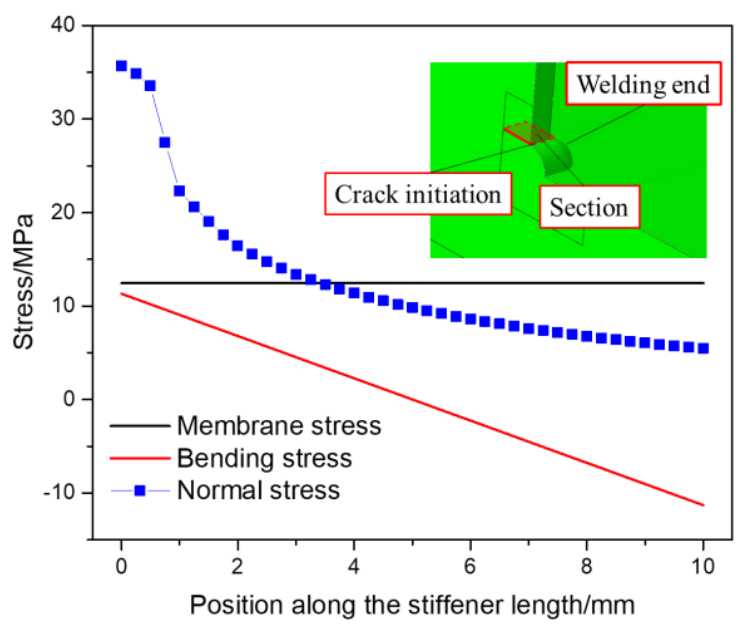

(a) $-500 \mathrm{~mm}$ 


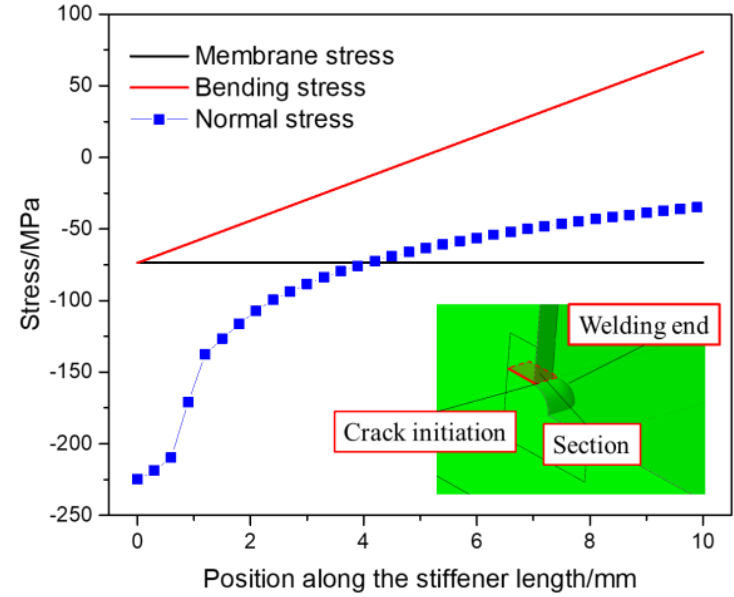

(b) $200 \mathrm{~mm}$

Fig. 8 Stress of welding end on the vertical stiffener

For the welding end on the vertical stiffener, the membrane stress, bending stress and normal stress of the cracking section when the wheel load was applied on the $-500 \mathrm{~mm}$ and $200 \mathrm{~mm}$ in transverse and the 13th static cases in longitudinal were depicted in Fig. 8. For wheel load on the $-500 \mathrm{~mm}$ in transverse, the bending stress of the cracking section was $12.5 \mathrm{MPa}$, while the membrane stress was almost identical to the bending stress, namely $11.3 \mathrm{MPa}$. It indicated that the fatigue cracking in this detail resulted from combination of the out-of-plane and in-plane deformation. These two kinds of deformation accounted for nearly same degree in fatigue damage. Meanwhile, the nonlinear stress caused by geometric structure increased the normal stress by $34.3 \%$. Similarly, for wheel load on the $200 \mathrm{~mm}$ in transverse, the bending stress of the cracking section was $-73.7 \mathrm{MPa}$, while the membrane stress was almost identical to the bending stress, namely -73.4MPa. Meanwhile, the nonlinear stress caused by geometric structure increased the normal stress by $34.4 \%$. Therefore, the cracking Type 2 of the deck-to-vertical stiffener weld, i.e., the crack initiated from the welding end on the vertical stiffener, was caused by the combined outof-plane and in-plane deformation under the wheel load.

\section{The fatigue repairing experiment of deck-to-vertical stiffener weld}

3.1. Experiment program

The fatigue repairing experiment was carried out on the deck-to-vertical stiffener weld. It's known that the fatigue cracking on the steel bridge deck mainly resulted from the local stress concentration on the details and local structures, thus local full-sized specimens were designed for fatigue experiment according to the fatigue detail in real bridges and relevant literatures [16]. The deck and vertical stiffener were welded by gas metal arc (GMA) welding. The welding leg of fillet weld with complete-joint-penetration (CJP) was $6 \mathrm{~mm}$. The geometric dimension of the specimen was shown in Fig. 9. A total of 6 specimens were designed including one repaired by re-welding, one by rewelding, hammering and polishing, one by drilling stop-holes, one by Carbon Fiber Reinforced Plastics(CFRP), one by re-welding and CFRP reinforcement, another by drilling stop-holes and CFRP reinforcement. Number them from SJ1 to SJ6 and the repairing workmanship was shown in Table 1. Some certain specimens during or after repairing process were illustrated in Fig. 10.

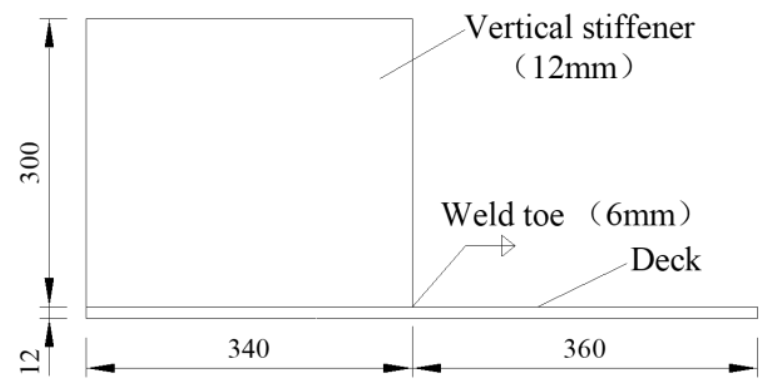

(a) Geometric dimension

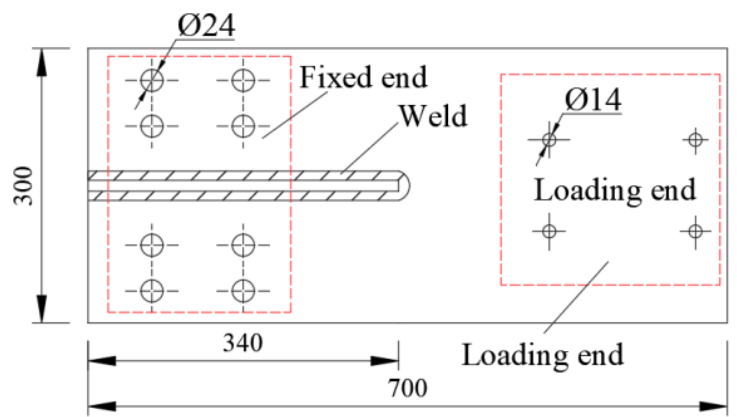

(b) Boundary condition

Fig. 9 The design of specimens (unit: $\mathrm{mm}$ )

Table 1

The repairing workmanship of the deck-to-vertical stiffener weld

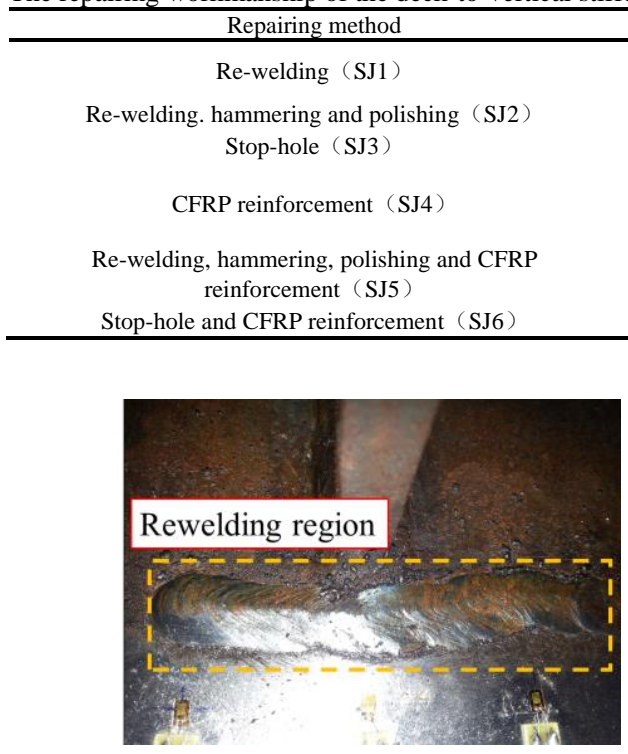

(a) SJ1

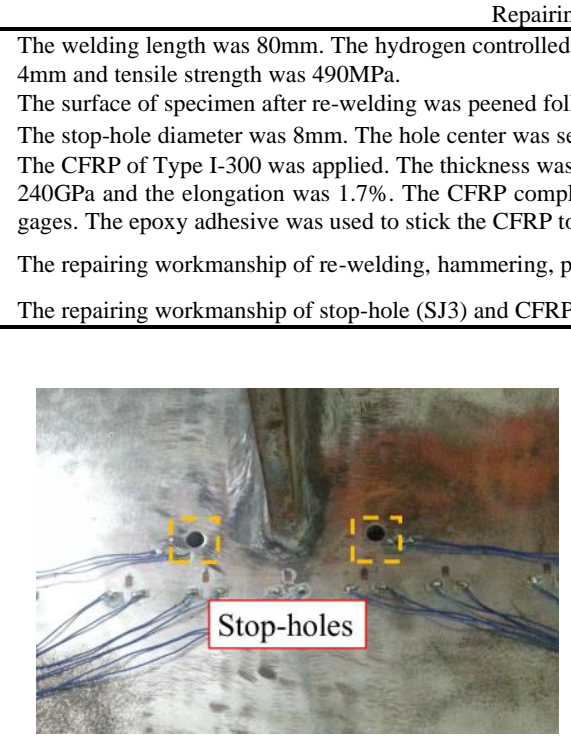

(b) $\mathrm{SJ} 3$

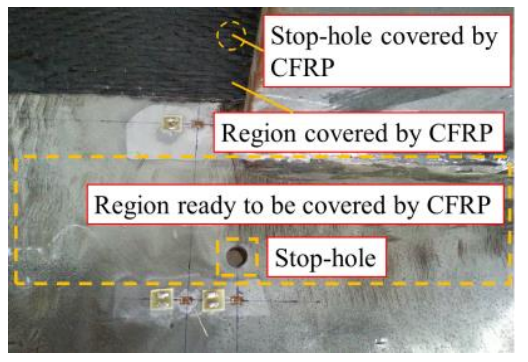

(c) SJ6

Fig. 10 Repairing process of certain specimens 
The bending load was applied on the specimen by eccentricity vibrating machine, which had widespread use in fatigue tests [17]. One side of the specimen was constrained on the reaction frame and the eccentricity vibrating machine was constrained on the other side. The harmonic vibration load was applied and the stress ratio $\mathrm{R}$ was equal to -1 . Adjust the load frequency to render the nominal stress range of welding end (D4 in Fig. 12) equal to $100 \mathrm{MPa}$ at the beginning of the fatigue test. The loading installation was shown in Fig. 11.

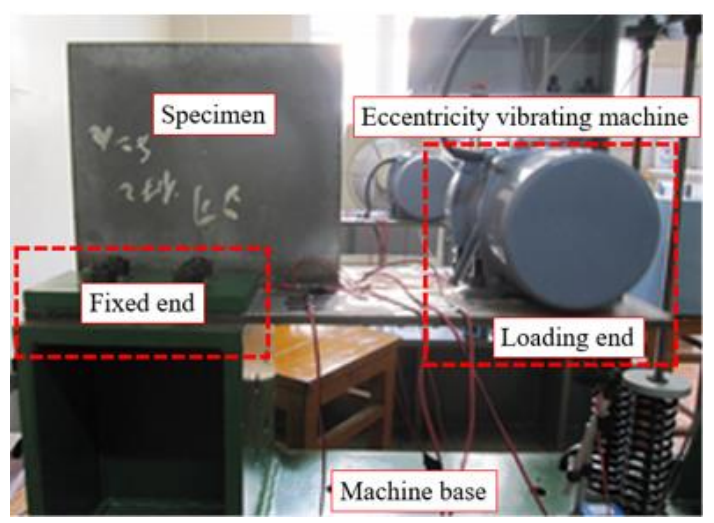

Fig. 11 The vibration loading machine

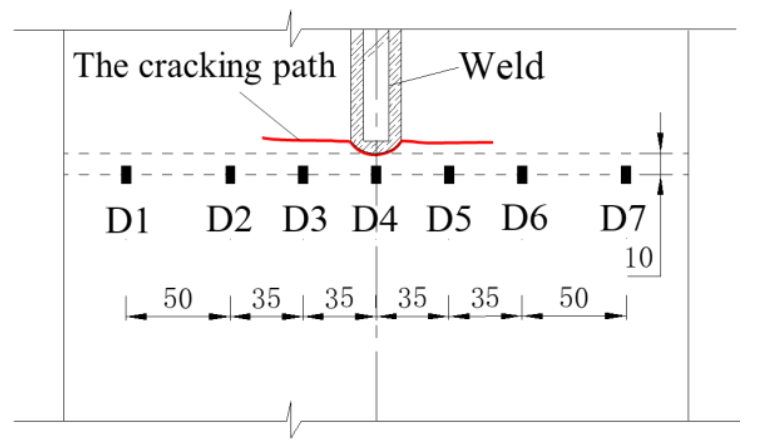

The cracks in the specimens were prefabricated by the eccentricity vibrating machine, and the repairing process was not carried out until the crack propagated into approximate $30 \mathrm{~mm}$. The cracks of all these specimens were observed to initiate from the welding end on the deck, i.e., the cracking Type 1. This was because the bending load was applied on the specimens and welding end was mainly endured bending stress. The load was applied to the specimen after repairing and discharged when the crack length reached 50mm. The strain gages were pasted on the specimens and shown in Fig. 12. Considering the cracking characteristics in real bridges, 7 gages were set along the transverse of the deck, which were $10 \mathrm{~mm}$ from the welding end to measure the nominal stress. The distance $10 \mathrm{~mm}$ was determined by the stress gradients of the welding end to ensure the nominal stress was not affected by the geometric discontinuity [18]. In the vicinity of the welding end, the space between the gages was comparatively smaller, namely $35 \mathrm{~mm}$. For gages far from the welding end, the space was $50 \mathrm{~mm}$.

\subsection{Change of stress ranges}

In the application of re-welding techniques, the cracking region was digged by pneumatic digger then the cracking section was welded again, thus the rewelding workmanship was a kind of complete repairing. It was known that the fatigue life of specimens repaired by re-welding would be much longer than that by the stop-hole and CFRP reinforcement. It could also be observed from the fatigue experiments that the stress histogram of specimen by re-welding (SJ1, SJ2) was long enough. Taking the specimen SJ1 by re-welding and specimen SJ2 by re-welding, hammering and polishing as examples, the initial, final stress ranges, final stress changes and change of stress ranges of different gages were shown in Table 2. The initial stress ranges refer to stress ranges of the testing position at the beginning of the fatigue loading and the final stress ranges refer to stress ranges when the fatigue loading ends. For SJ1, the final stress range of measuring points (D3-D5) in the vicinity of the welding end declined. The final stress range of D4 corresponding to the initiation of cracking on the welding end dropped a lot, namely $40.9 \%$. The final stress ranges of measuring points where the crack tip hadn't reached yet increased dramatically. For SJ2 after hammering and polishing, the final stress range of D4 decreased by $53.1 \%$, while change rate of other measuring points which experienced increase in stress ranges was much smaller than that of SJ1. The change of stress ranges was smooth, showing that the stress distribution of weld after hammering and polishing was more favorable.

Fig. 12 Measuring points（unit: $\mathrm{mm}$ )

Table 2

Comparison of stress ranges

\begin{tabular}{|c|c|c|c|c|c|c|c|c|}
\hline \multirow[t]{2}{*}{ Number } & \multicolumn{2}{|c|}{ Initial stress range $(\mathrm{MPa})$} & \multicolumn{2}{|c|}{ Final stress range $(\mathrm{MPa})$} & \multirow{2}{*}{$\begin{array}{l}\text { Stress range change } \\
\text { SJ1 }\end{array}$} & \multirow{2}{*}{$\frac{(\mathrm{MPa})}{\mathrm{SJ} 2}$} & \multicolumn{2}{|c|}{ Change rate $(\%)$} \\
\hline & SJ1 & $\mathrm{SJ} 2$ & SJ1 & $\mathrm{SJ} 2$ & & & SJ1 & $\mathrm{SJ} 2$ \\
\hline D1 & 61.8 & 54.5 & 97.8 & 62.9 & 36.1 & 8.4 & 58.4 & 15.4 \\
\hline D2 & 64.7 & 64.7 & 93.0 & 81.0 & 28.3 & 16.3 & 43.7 & 25.2 \\
\hline D3 & 81.7 & 78.2 & 68.3 & 93.4 & -13.4 & 15.2 & -16.4 & 19.4 \\
\hline D4 & 100.2 & 102.8 & 59.2 & 48.2 & -41.0 & -54.6 & -40.9 & -53.1 \\
\hline D5 & 79.4 & 77.9 & 62.3 & 63.0 & -17.1 & -14.9 & -21.6 & -19.1 \\
\hline D6 & 67.6 & 66.2 & 94.3 & 78.3 & 26.8 & 12.1 & 39.6 & 18.3 \\
\hline D7 & 60.5 & 56.1 & 97.0 & 67.4 & 36.4 & 11.3 & 60.2 & 20.1 \\
\hline
\end{tabular}

The Fig. 13 illustrated the curves of stress ranges in SJ1 and SJ2 changing with loading cycles. The cracks initiated from the welding end on the deck and then propagated transverse to the deck. The stress ranges of measuring points in the vicinity of the welding end declined and the rest increased. This was because the initiation of crack cut off the stress flow on the deck surface, resulting in the decrease of stress range where the crack tip reached and increase of other measuring points because of the stress redistribution. For specimen SJ1, the stress range of D3 and D5 declined quickly with the decrease of stress range of D4, showing that the crack propagated fast after initiation on the welding end and reached length of $35 \mathrm{~mm}$ which corresponded to the position of D3 and D5. For specimen SJ2, after the decline of stress range of D4, the stress range of D5 increased first then decreased during certain period of fatigue cycles. This was because the crack tip didn't propagate to the position of D5 before the stress range of D5 reached the peak and the stress redistribution resulted in the increase of stress range. When the crack tip reached the position of D5, the stress range declined. The stress range of D3 increased all the time, indicating that the crack tip never propagated to D3 throughout the loading procedure. The crack developed asymmetrically on two sides of the vertical stiffener. In analysis of stress range in specimen SJ1 and specimen SJ2, the residual stress of weld on specimen SJ1 was great because SJ1 was not hammered and polished after rewelding. The crack propagated quickly and exceeded the length of re-welding region after initiation on the welding toe. But cracking rate of $\mathrm{SJ} 2$ was comparatively slower since welding residual stress was removed, so it was necessary to hammer and polish the weld after re-welding to reduce the residual stress. 


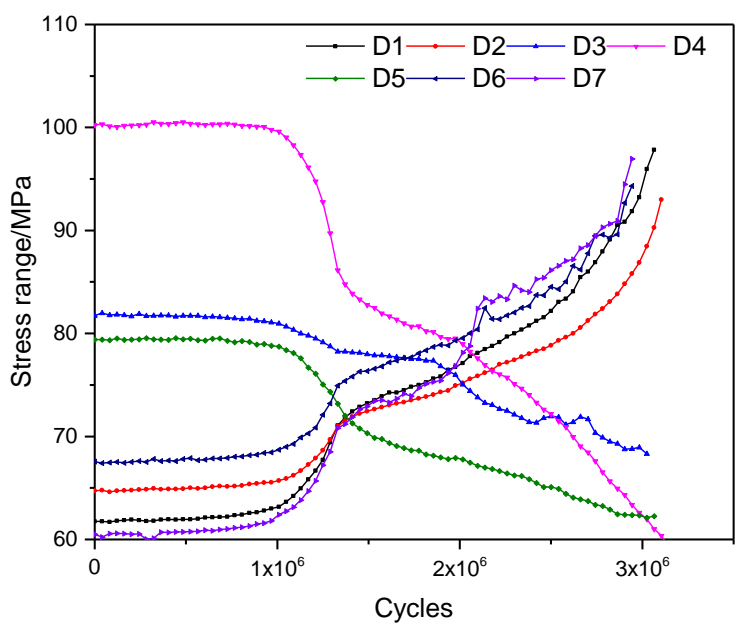

(a) SJ1

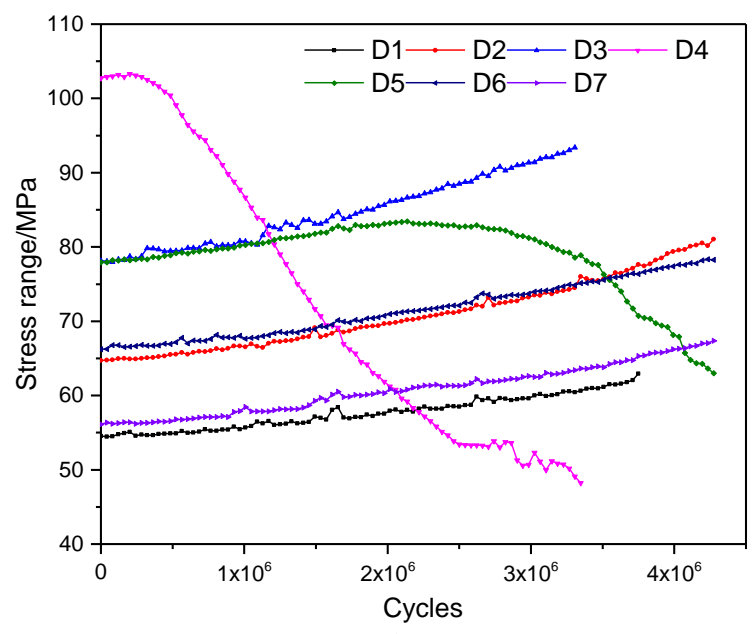

(a) $\mathrm{SJ} 2$

Fig. 13 Change of stress ranges

\subsection{Fatigue life}

The re-welding technique was a kind of complete fatigue repairing method, while the stop-hole and CFRP reinforcement were temporary. The different repairing purpose resulted in substantial discrepancies of fatigue life. Therefore, the comparison of fatigue life was carried out on the specimens with the rewelding technique (SJ1, SJ2 and SJ5) and without the re-welding technique (SJ3, SJ4 and SJ6). The relationship of crack length-to-fatigue cycles was depicted in Fig. 14, where in the legend "left" means crack tip on the left of the vertical stiffener and "right" means crack tip on the right.

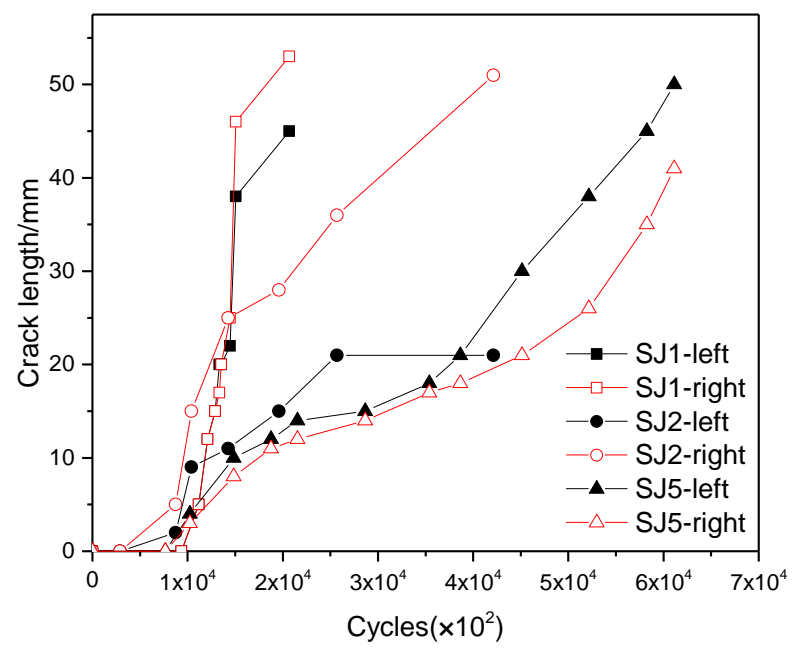

(a) $\mathrm{SJ} 1, \mathrm{SJ} 2, \mathrm{SJ} 5$

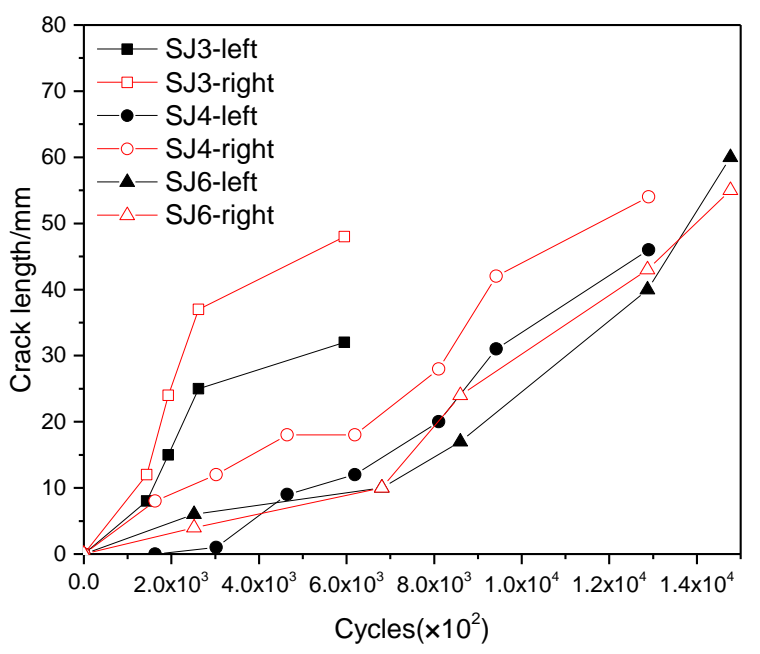

(b) $\mathrm{SJ} 3, \mathrm{SJ} 4, \mathrm{SJ} 6$

Fig. 14 Fatigue life

In Fig. 14(a), the fatigue life of SJ2 was generally greater than that of SJ1. With crack length increasing, especially when the crack tip approached and exceeded the boundary of re-welding region, the curves of SJ1 and SJ2 separated from each other and great difference could be observed. It meant the welding residual stress weakened fatigue life seriously. Besides, hammering and polishing after re-welding could reduce the residual stress and slow down the cracking rate. The cracking rate of SJ5 was comparatively small and its fatigue life was usually greater than that of SJ1 and SJ2 under the same crack length. It was indicated that by reinforcement of CFRP, the material stuck to the deck by epoxy adhesive was subjected to fatigue load together with the structure, thus restraining the open of crack tip and improving stress distribution on the welding end. By the comparison of SJ5 by re-welding, hammering, polishing and CFRP reinforcement, SJ2 by re-welding, hammering and polishing, and SJ4 by CFRP reinforcement, the cracking rate of SJ5 was comparatively small, indicating that repairing effect by simultaneous two techniques was more favorable than that of a single technique.

In Fig. 14(b), the stop-hole of SJ3 removed the original crack tip and no crack propagation occurred before the new crack initiated. Then fatigue cracks initiated from the edge of hole, which was the new position of stress concentration, after a certain period of stress cycles. The propagation rate of SJ3 was greater than that of SJ4 and SJ6, indicating that the repairing effect of stophole was comparatively unfavorable. For SJ4 by CFRP reinforcement and SJ6 by stop-hole and CFRP reinforcement, the curves were close to each other, indicating that repairing effects were generally the same. According to the relationship of crack length-cycles, the fatigue life of SJ6 was longer under the same crack length, thus repairing effect by simultaneous two techniques was more favorable than that of a single techniques. Moreover, the fatigue life of SJ2 by re-welding and polishing was 7.1 times that of SJ3 by stop-hole and 3.3 times that of SJ4 by CFRP reinforcement, indicating that the repairing effects of complete method were obviously more favorable than that of temporary method.

\section{Influences of fatigue repairing effects}

\subsection{Welding residual stress}

The welding residual stress was one of the most significant factors affecting the repairing effects of re-welding. The experiment results in section 3 also showed that the fatigue life of SJ2 after eliminating the residual stress was much longer than that of SJ1. The heats during welding of steel deck changed sharply both in time and space and were a kind of typical nonlinear transient transfer, thus the welding stress field was usually simulated by thermal elastoplastic analysis and the incremental method was applied to solve the temperature field and stress field. Based on the welding plug-in AWI (ABAQUS Welding Interface) which was developed by 3DEXPERIENCE Accompany, the rewelding process was modeled and the residual stress distribution was analyzed. 


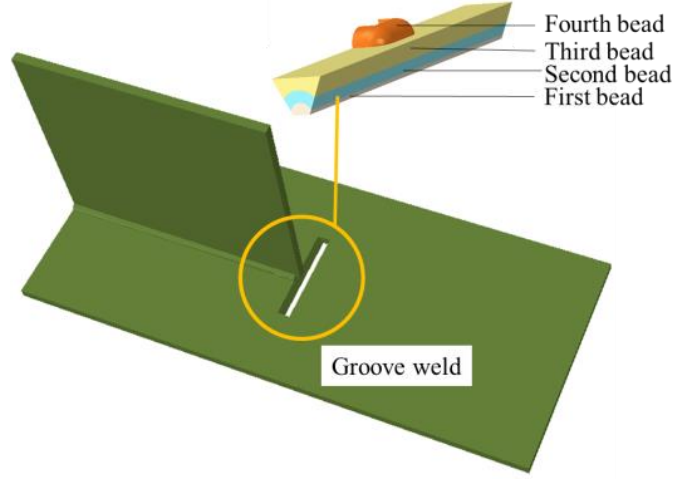

Fig. 15 The re-welding model

The deck-to-vertical stiffener weld on steel bridge deck was modeled by ABAQUS and then introduced to the plug-in AWI for welding simulation. The model by re-welding was shown in Fig. 15. According to the specimens in section 3 , the length of deck was $700 \mathrm{~mm}$ and width was $300 \mathrm{~mm}$. To simulate the re-welding workmanship in the experiment, the deck was beveled on both sides of vertical stiffener and length of the groove weld was $30 \mathrm{~mm}$ on each side. The welding process was completed by four beads. In the heat affected zone (HAZ), the temperature gradient was great and stress changed dramatically, thus the mesh of the weld and re-welding region was refined. Six degrees of freedom (DOFs) of the bottom surface were restrained to simulate the platform in the workshop. The DC3D8 element was used for thermal analysis, and C3D8R for thermal stress analysis. Five different mesh sizes were applied to verify the accuracy of FE analysis of local and full-sized specimen. The hex element which owned a size of $1 \mathrm{~mm}, 2 \mathrm{~mm}, 3 \mathrm{~mm}, 4 \mathrm{~mm}$ and $5 \mathrm{~mm}$ was calculated separately. It could be observed that the greatest stress difference was between the mesh size of $3 \mathrm{~mm}$ and $4 \mathrm{~mm}$, which was $14.8 \%$. The stress curves with mesh size of $2 \mathrm{~mm}$ and $3 \mathrm{~mm}$ were close to that with mesh sized of $1 \mathrm{~mm}$, which was assumed to have the greatest accuracy. The stress curves showed a convergent solution for FE analysis with different mesh sizes. Therefore, the mesh size of $2 \mathrm{~mm}$ was applied to the FE model for calculating accuracy and efficiency. The technique of element birth and death was applied to simulate the process of welding, which was realized by activation and inactivation of element sets in sequence. The welding speed was $10 \mathrm{~mm} / \mathrm{s}$ and interval of each time step was $0.2 \mathrm{~s}$. A total of 61 steps were set for heating and then the specimen was cooled in room temperature.

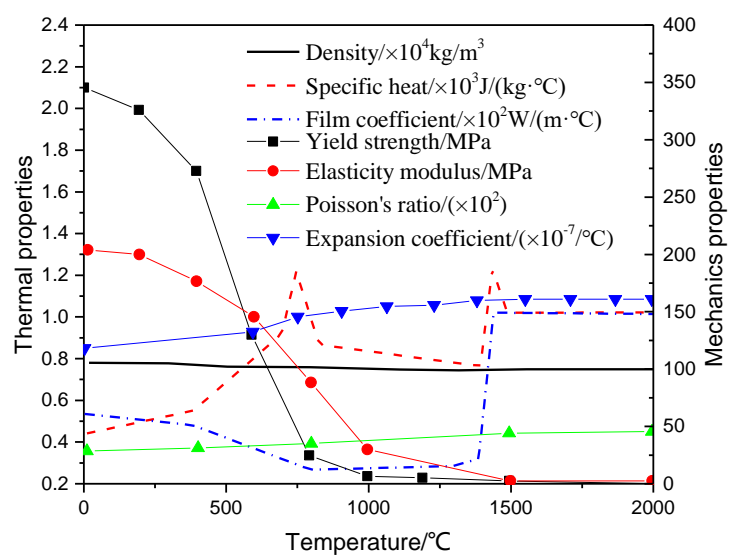

Fig. 16 The physical properties

The thermophysical and thermodynamical parameters of Q345 steel [19] were depicted in Fig. 16. Considering two forms of heat transfer, namely heat conduction and heat convection, the Stefan-Boltzmann constant was equal to $5.67 \times 10^{-11} \mathrm{~mJ} / \mathrm{s} / \mathrm{mm}^{2} / \mathrm{K}^{4}$, the absolute zero was $-273.15^{\circ} \mathrm{C}$, the room temperature was $21.1^{\circ} \mathrm{C}$ and the convective heat coefficients was $0.013 \mathrm{~mJ} / \mathrm{s} / \mathrm{mm}^{2} / \mathrm{K}^{4}$.

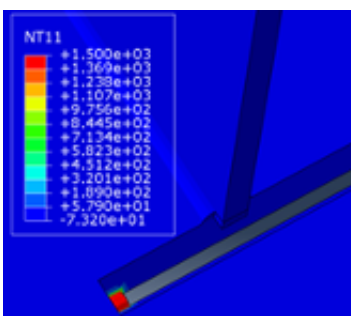

(a) Step 1

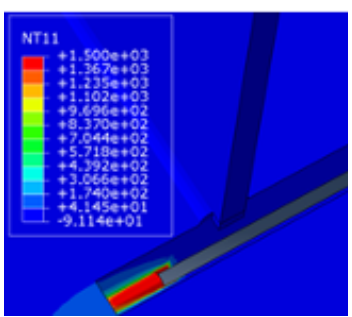

(b) Step 5

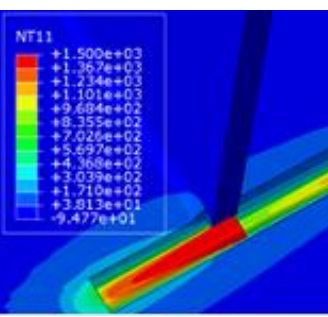

(c) Step 31

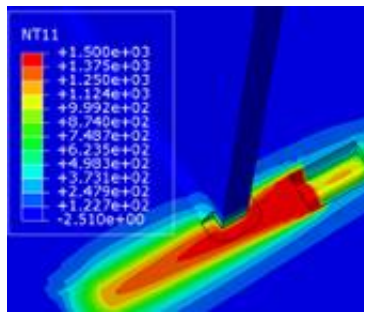

(d) Step 56

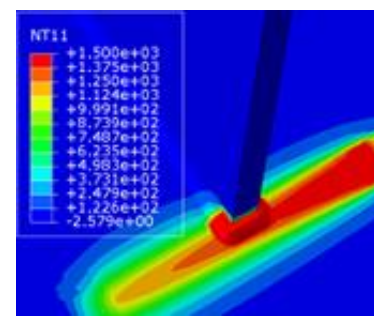

(e) Step 61

Fig. 17 The temperature field

The temperature contour during the welding process was shown in Fig. 17. It could be seen that the temperature field of the specimen changed constantly with the moving of heat source. The temperature of the specimen was unstable at first and heat up quickly, then temperature of quasi stable state would be formed on the specimen. The temperature of specimen changed over time while the temperature field moved with the heat source in a certain pattern. The temperature gradient was steep in front of the heat source and gentle behind it.

The Von Mises stress of specimen after welding and cooling was illustrated in Fig. 18. During the welding process, stress of melting weld was very small while stress of regions surrounding the weld pool was close to the yield strength of steel. Therefore, great residual stress was generated in the welds. The stress concentration caused by geometric construction was avoided and section stress $10 \mathrm{~mm}$ to the weld toe was analyzed. The stress path was $100 \mathrm{~mm}$ long on each side of the vertical stiffener and the nominal stress of bottom, middle and top surface was extracted and shown in Fig. 19. It could be seen that the residual stress on the top surface was greater than that of the middle and bottom surface. This was because specimen was re-welded from the bottom weld pass to the top one. The cooling time of various beads was different during the welding and the beads welded previously were solidified and had suitable strength, which would stop free expansion of beads welded latterly and induce the plastic deformation in the weld. When the weld as a whole cooled down, shrinkage of beads welded latterly was restrained by the solidified bead. The tensile stress was generated in the beads welded latterly and compressive stress was generated in the beads welded previously. This also embodied in the phenomenon that residual stress on the top surface increased dramatically in the weld while it declined sharply on the bottom surface. The welding end welded at last generated tensile stress on the top surface during cooling and compressive stress on the bottom surface which cooled down previously.

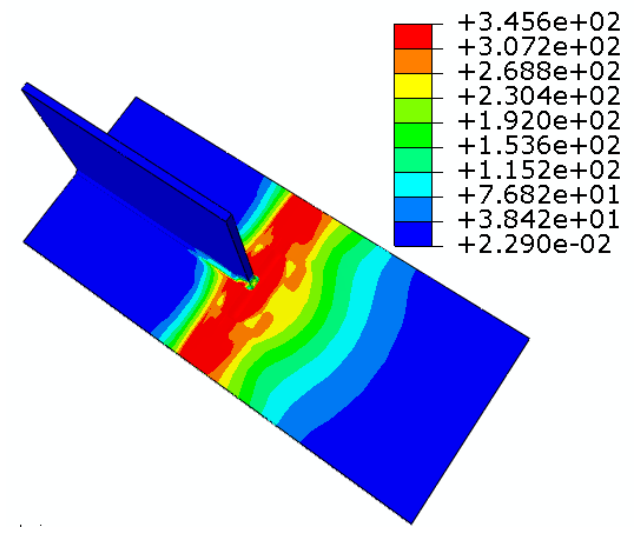

Fig. 18 Residual Von Mises stress after cooling (unit: MPa) 


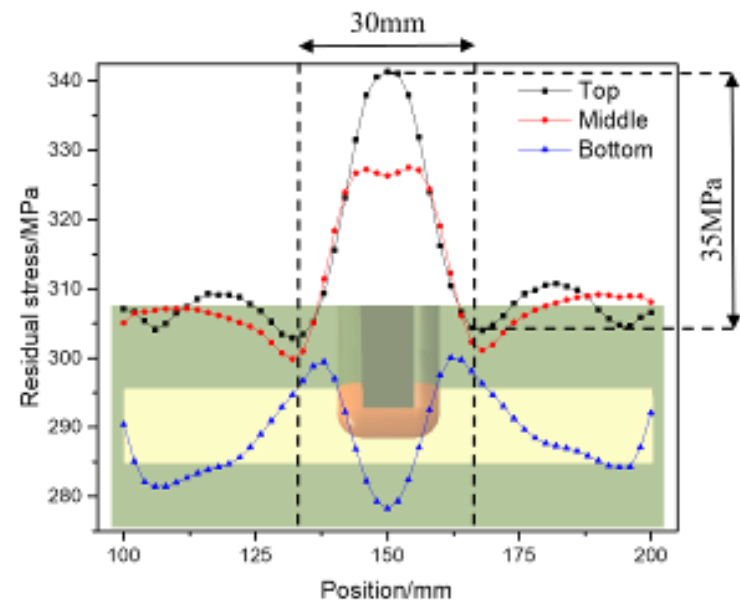

Fig. 19 Residual stress of the deck

It could be seen in Fig. 19 that the peak of residual stress on the deck surface approached the yield strength of steel. The stress changed dramatically in the range of approximate $30 \mathrm{~mm}$ on the welding end and the amplitude was $35 \mathrm{MPa}$. The crack of deck-to-vertical stiffener weld generally initiated from the weld toe and propagated to both sides of the deck. As the residual tensile stress had already reached the yield stress of steel on the weld, the fatigue limit would be achieved and weld would crack quickly under the fatigue load. This also verified the experiment results of SJ1 and SJ2. Therefore, it was necessary to hammer and polish the weld region after re-welding to get rid of the tensile stress and render the weld surface smooth.

\subsection{Parameters of stop-hole}

The position and diameter of the stop-hole were significant factors influencing the repairing effects. To study the influence of different stop-hole workmanship on the fatigue repairing of the deck-to-vertical stiffener weld, five stop-hole positions, namely $-0.5 \mathrm{D}, 0,0.5 \mathrm{D}, 1.0 \mathrm{D}$ and $1.0 \mathrm{t}$, and three stop-hole diameter, namely $6 \mathrm{~mm}, 8 \mathrm{~mm}$ and $10 \mathrm{~mm}$ were considered. D referred to diameter of the stop-hole and $t$ referred to deck thickness. A total of 15 working conditions were modeled, and the dimension of the specimen and loading conditions were consistent with the experiment in Section 3. The specific information of working conditions was illustrated in Table 3.

Table 3

Working conditions of the stop hole

\begin{tabular}{cccccc}
\hline & \multicolumn{5}{c}{ Stop-hole position X(mm) } \\
Stop-hole diameter $\mathrm{D}(\mathrm{mm})$ & $-0.5 \mathrm{D}$ & 0 & $0.5 \mathrm{D}$ & $1.0 \mathrm{D}$ & $1.0 \mathrm{t}$ \\
\hline 6 & -3 & 0 & 3 & 6 & 12 \\
8 & -4 & 0 & 4 & 8 & 12 \\
10 & -5 & 0 & 5 & 10 & 12 \\
\hline
\end{tabular}

The specimen was modeled by ABAQUS and extended finite element method (XFEM) was applied to solve the stress singularity at crack tip. The fatigue crack section was considered to be semi-elliptical in deck thickness [16]. Therefore, the ratio of minor to major axis lengths (b/a) was 0.33 according to previous statistics, as shown in Fig. 20. The semi-major axis length and the semi-minor axis length were defined as approximate $32 \mathrm{~mm}$ and $12 \mathrm{~mm}$ considering the actual crack length in the current experiment. The interaction between the crack and the model is "hard contact". Element types C3D8R and C3D10 were adopted. The mesh size of the model was $20 \mathrm{~mm}$ (overall). The element size was refined to be $2 \mathrm{~mm}$ at the welding end by C3D8R. In the width of $20 \mathrm{~mm}$ out from the weld, C3D10 was adopted to model the transition region.

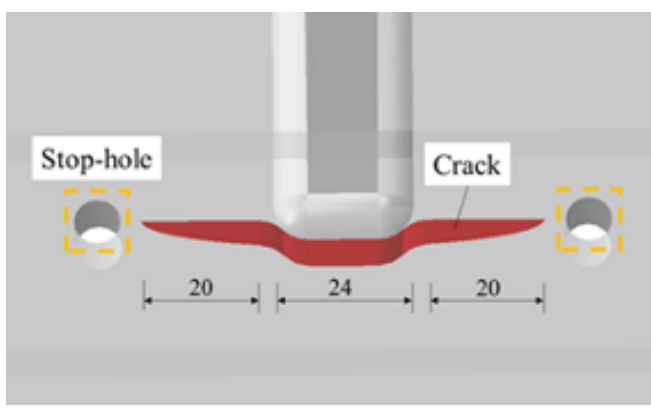

Fig. 20 Set of the crack $(\mathrm{mm})$

According to the fatigue analysis in the current experiment and previous studies, stress of $0.35 \mathrm{MPa}$ was applied on four loading surfaces with length of $45 \mathrm{~mm}$ and width of $40 \mathrm{~mm}$. It caused a stress of $50 \mathrm{MPa}$ at the center of the model (with no crack) at some $10 \mathrm{~mm}$ from the welding end. Fixed restraint was applied within a distance of $225 \mathrm{~mm}$ and $136 \mathrm{~mm}$ from the deck edge, 6 DOFs were constrained. No constraints were set in other parts (Fig. 21).

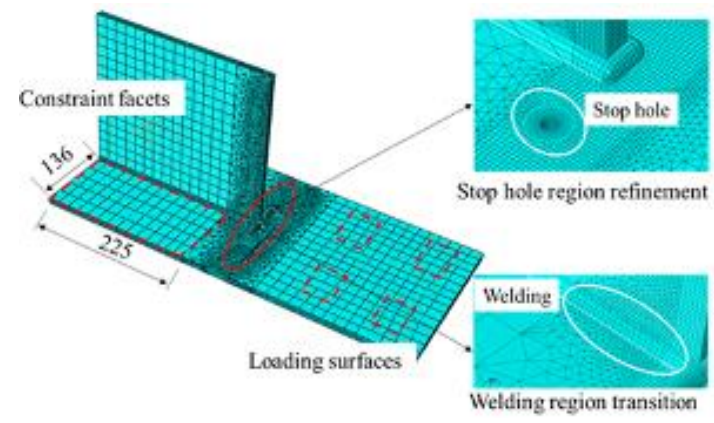

Fig. 21 Model of the stop-hole

When the diameter of stop-hole equaled to $6 \mathrm{~mm}$, stress changing from the stop-hole edge to the model edge with different stop-hole positions was shown in Fig. 22. Only one side of stress was drawn as the model was symmetrical by the vertical stiffener. It could be seen that the trend of stress changes with different stop-hole positions was the same with stress dropping down sharply near the stop-hole edge. Great stress gradients were generated and the maximum stress was observed on the stop-hole edge. Then decline of stress slowed down at certain distance (approximate $10 \mathrm{~mm}$ ) from the stop-hole edge and converged eventually. The stress peak decreased with increasing of stop-hole position. When the stop-hole position was greater than $0.5 \mathrm{D}$, the decline of peak stress was gradually not so obvious.

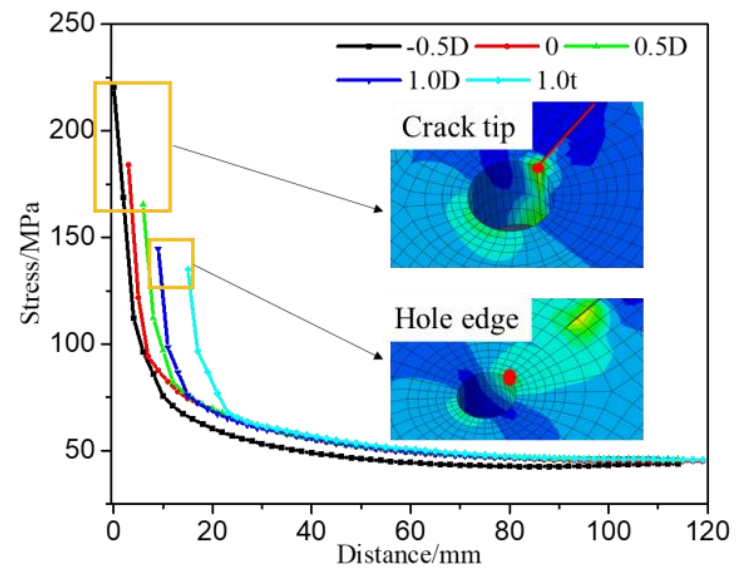

Fig. 22 The stress change with $6 \mathrm{~mm}$ stop hole

The original crack was removed by the stop-hole while new stress concentration was generated on the stop-hole edge in the direction of initial cracking propagation. So the stress on the stop-hole edge was obtained and illustrated in Fig. 23. It could be seen that the greater the stop-hole diameter was, the stress of the stop-hole edge was smaller, which indicated a more favorable repairing effects. Therefore, greater stop-hole diameter was recommended in 
fatigue repairing of real bridges. But as greater stop-hole diameter would weaken the bearing capacity of the section, it should be smaller than a certain limit. The peak stress at the new initiation decreased with increasing of stophole position except for particular cases in the position of 0 when hole diameter was $8 \mathrm{~mm}$ and $10 \mathrm{~mm}$. The reason of smaller peak stress at the hole edge was that the distance between the crack tip and the hole edge was too long to have great influence on the hole edge. However, the crack was not removed and would continue to propagate to shorten the distance. Moreover, the crack extension path was uncertain and crack might even propagate away from the stop-hole. These results led to unfavorable crack-stopping effects. The change of peak stress with stop-hole position had an inflection point at $\mathrm{X}=0.5 \mathrm{D}$ (stophole diameter equaled to $8 \mathrm{~mm}$ and $10 \mathrm{~mm}$ ). In this case, the stop-hole covered the crack tip and removed the plastic zone around the crack tip. Therefore, $\mathrm{X}=$ $0.5 \mathrm{D}$ was suggested as being a reasonable stop-hole position.

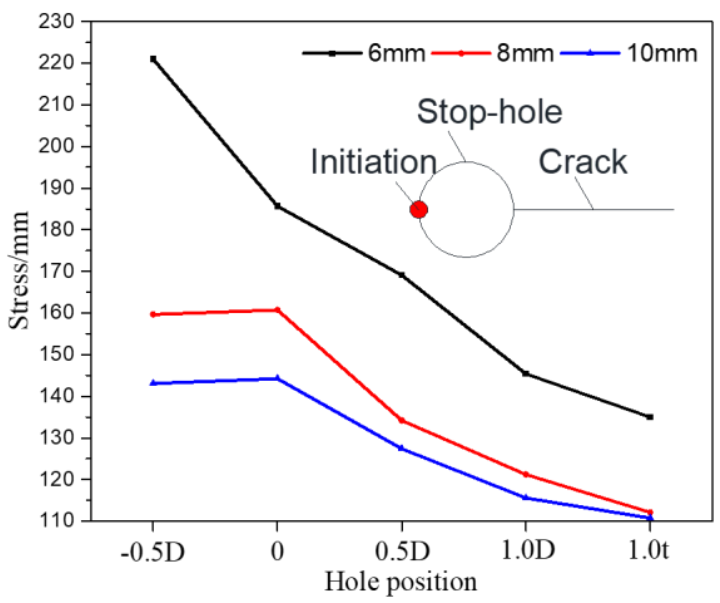

Fig. 23 Stress peak of the stop hole

\subsection{Parameters of CFRP reinforcement}

The covering area of CFRP on the crack influenced the restriction on crack propagation. Moreover, the favorable mechanical property of CFRP improved the repairing performance. Therefore, different transverse length $(20 \mathrm{~mm}, 25 \mathrm{~mm}$, $30 \mathrm{~mm}, 60 \mathrm{~mm}, 90 \mathrm{~mm}, 100 \mathrm{~mm}$ and $130 \mathrm{~mm})$ and elasticity modulus $(240 \mathrm{GPa}$ and 210GPa) of CFRP were considered, and totally 12 working conditions were shown in Table 4 . The longitudinal length of CFRP was set as constant $140 \mathrm{~mm}$.

Table 4

Working conditions of CFRP

\begin{tabular}{ccccccc}
\hline Elasticity modulus (GPa) & \multicolumn{5}{c}{ Transverse length /mm } \\
\hline 240 & 20 & 25 & 30 & 60 & 90 & 130 \\
210 & 20 & 25 & 30 & 60 & 90 & 130 \\
\hline
\end{tabular}

The model of deck-to-vertical stiffener weld reinforced by CFRP was shown in Fig. 24. The model size was consistent with the experiment in Section 3. The parameter of CFRP was in accordance with the specification [20]. The thickness of CFRP was $0.17 \mathrm{~mm}$ and Poisson's ratio was 0.261 . As it could be assumed that there was no relative slippage between the CFRP and deck [21], a kind of constrain named "TIE" was set between the two in the model. The crack shape, mesh size and loading conditions were referred to the stop-hole model in Section 4.2 and the CFRP, modeled by S4R of shell elements, had a mesh size of $2 \mathrm{~mm}$. The stress of the cracking section from crack tip to the model edge was obtained and shown in Fig. 25.

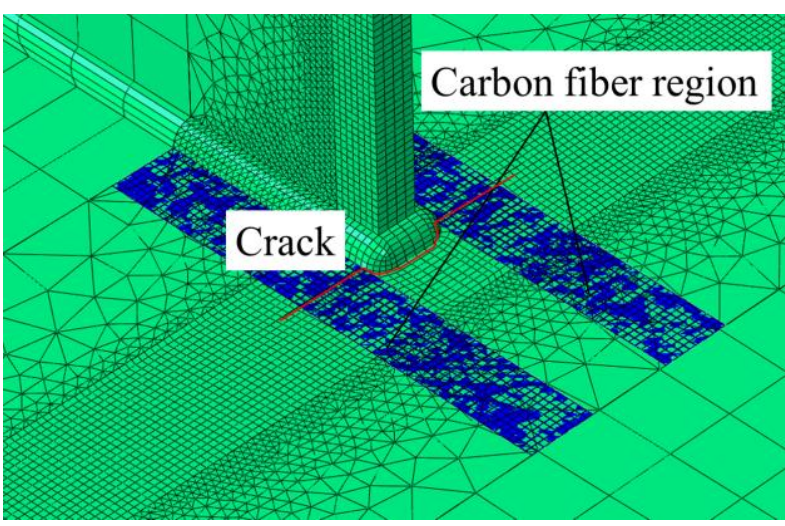

Fig. 24 Model of the CFRP

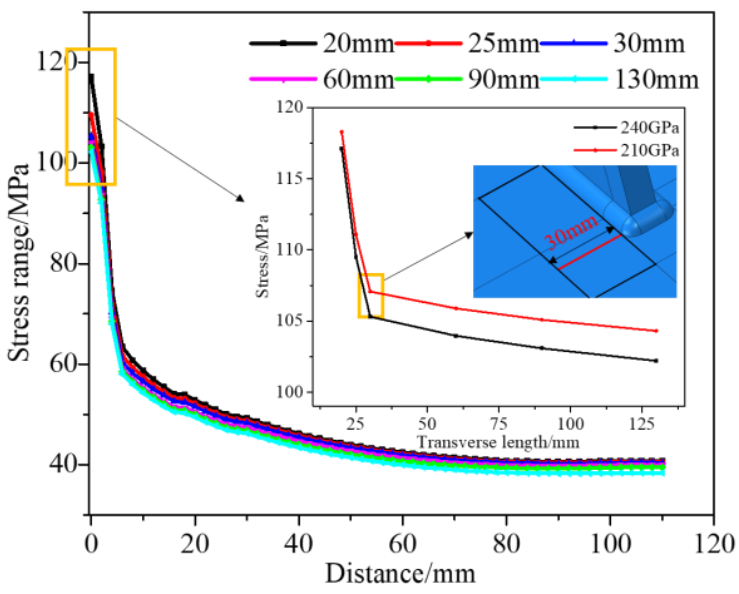

Fig. 25 The stress of cracking section with various parameters

Fig. 25 depicted stress of cracking section changing with the transverse length of CFRP when the elasticity modulus equaled to $240 \mathrm{GPa}$, which was similar to the stop-hole model. Stress declined dramatically near the crack. Great stress gradients were generated and the maximum stress was observed on the crack tip. Then decline of stress slowed down at certain distance (approximate 10mm) from the stop-hole edge and converged eventually. By comparison of stress with different CFRP length, the longer the length was, the smaller the crack propagation would be when the CFRP length was less than $30 \mathrm{~mm}$. It indicated that greater covering area of CFRP contributed to more favorable repairing performance. When the CFRP length was greater than $30 \mathrm{~mm}$, i.e., the CFRP completely covered the crack surface, increase of covering area didn't have a favorable performance to decline stress of cracking section. Therefore, length of CFRP which was able to cover the crack surface was enough in theory. However, the crack propagated with increment of fatigue cycles and the crack length would excess the covering area of CFRP, so it was necessary to apply greater length of CFRP than crack length according to real conditions.

It could also be observed that stress change of CFRP with two different elasticity modulus were almost the same, but CFRP with 240GPa of elasticity modulus led to smaller stress than that with $210 \mathrm{GPa}$ of elasticity modulus, so preliminary conclusion could be drawn that greater elasticity modulus could contribute to smaller stress. CFRP with greater elasticity modulus was recommended in real fatigue repairing.

\section{Conclusions}

Based on the experiments and FEM analysis, the following preliminary conclusions can be obtained.

(1) Cracks of welding end on the deck was induced by out of plane deformation and that on the vertical stiffener was induced by combined out-ofplane and in-plane deformation, which led to the same degree of fatigue damage on this detail. Stress ranges of welding on the vertical stiffener were greater than that on the deck, thus welding end on the vertical stiffener was more prone to cracking with identical material and welding craftsmanship. 
(2) The cracking rate of re-welding model with polishing was much smaller than that without hammering and polishing, so it could be speculated that welding residual stress was reduced. The analysis of residual indicated that residual tensile stress reached yield strength of steel after re-welding, thus it's necessary to hammer and polish the re-welding area to improve the fatigue repairing performance.

(3) The new stress concentration appeared at the stop-hole edge after remove of crack. The greater the stop-hole diameter was, the smaller the stress of the stop-hole edge would be. But oversized diameter weakened the bearing capacity of section, so it should be smaller than a certain limit. The crack was not removed and might propagate away from the stop-hole if the stop-hole position was oversized, thus the stop-hole position which was half of the hole diameter from the crack tip was recommended.

(4) The greater the elasticity modulus of CFRP was, the more significantly it decreased stress at the crack tip. The greater the area covering the crack was,

\section{References}

[1] Seo J., Phares B. and Wipf T.J., "Lateral live-load distribution characteristics of simply supported steel girder bridges loaded with implements of husbandry", Journal of Bridge Engineering, 19(2), 04013021, 2013

[2] Ji B., Liu R., Chen C., Maeno H. and Chen X., "Evaluation on root-deck fatigue of orthotropic steel bridge deck", Journal of Constructional Steel Research, 90(5), 174-183, 2013.

[3] Kim I.T., "Fatigue strength improvement of longitudinal fillet welded out-of-plane gusset joints using air blast cleaning treatment”, International Journal of Fatigue, 48(2), 289-299, 2013

[4] Steel Structure Committee of Civil Society, Report of Thick Plate Welding Joint Related Research, Japan, 2007. (in Japanese)

[5] Alemdar F., Gangel R., Matamoros A., Bennett C., Barrett-Gonzalez R., Rolfe S. and Liu H., "Use of CFRP overlays to repair fatigue damage in steel plates under tension loading", Journal of Composites for Construction, 18(4), 04013052, 2013.

[6] Alemdar F., Nagati D., Matamoros A., Bennett C. and Rolfe S., "Repairing distortioninduced fatigue cracks in steel bridge girders using angles-with-plate retrofit technique. I: Physical simulations", Journal of Structural Engineering, 140(5), 04014003, 2013.

[7] Tabrizi S., Kazem H., Rizkalla S. and Kobayashi A., "New small-diameter CFRP materia for flexural strengthening of steel bridge girders", Construction and Building Materials, 95, 748-756, 2015.

[8] Aljabar N.J., Zhao X.L., Al-Mahaidi R., Ghafoori E., Motavalli M. and Powers N., "Effect of crack orientation on fatigue behavior of CFRP-strengthened steel plates", Composite Structures, 152, 295-305, 2016

[9] Crain J., Simmons G., Bennett C., Barrett-Gonzalez R., Matamoros A.B. and Rolfe S.T., "Development of a technique to improve fatigue lives of crack-stop holes in steel bridges", Transportation Research Record Journal of the Transportation Research Board, 2200, 69-77, 2010.

[10] Kim Y.J. and Harries K.A., "Fatigue behavior of damaged steel beams repaired with CFRP strips", Engineering Structures, 33(5), 1491-1502, 2011.

[11] Park H.C., Lee C.H. and Chang K.H., "Strengthening a damaged steel girder bridge by the replacement repair welding", KSCE Journal of Civil Engineering, 16(7), 1243-1249, 2012.

[12] Ogasawara T., Iguchi S., Uchida D., Okumura M., Katano S., Saitou S., Hayashi N. and Matsushita H., "The fatigue maintenance method for the welding end of vertical stiffener on the steel bridge and steel lifting equipment", Technique of the Bridge Symposium Report, 2016. (In Japanese)

[13] Fu Z., Ji B., Wang Y. and Xu J., "Fatigue performance of the U-rib and roof weld in steel bridge decks with corner braces", Steel and Composite Structures, 26(1), 103-113, 2018

[14] JTG D64-2015, "Specifications for Design of Highway Steel Bridge," Ministry of Transport of the People's Republic of China, 2015. (In Chinese).

[15] Jiang X.L., Zeng G.L. and Tan J.H., "Structural reliability analysis of a steel truss bridge based on the monitoring data", Applied Mechanics \& Materials, 105-107, 1342-1345, 2011.

[16] Yang M., Ji B., Yuanzhou Z. and Fu Z., "Fatigue behavior and strength evaluation of vertical stiffener welded joint in orthotropic steel decks", Engineering Failure Analysis, 70, 222-236, 2016.

[17] Baik B., Yamada K. and Ishikawa, T., "Fatigue crack propagation analysis for welded joint subjected to bending", International Journal of Fatigue, 33(5), 746-758, 2016.

[18] Fu Z., Ji B., Kong X. and Chen X., "Grinding treatment effect on rib-to-roof weld fatigue performance of steel bridge decks", Journal of Constructional Steel Research, 129, 163-170, 2017.

[19] Zhao Q. and Wu C., "Numerical analysis of welding residual stress of u-rib stiffened plate", Engineering Mechanics, 46(8), 262-268, 2012. (In Chinese)

[20] Specifications for Strengthening Design of Highway Bridges, JTGT J22-2008, 2008. (In Chinese)

[21] Risan H.K., Harba I.S.I., Abdulridha A.J., "Numerical analysis of RC wall with opening strengthened by CFRP subjected to eccentric loads", Journal of the Croatian Association of Civil Engineers, 69(7), 573-580, 2017. the greater the effects that CFRP stopped crack propagation would be. When the CFRP completely covered the crack surface, increase of covering area didn't have a favorable performance to decline stress of cracking section. The length of CFRP was suggested to be greater than crack length based on real conditions.

(5) The re-welding technique removed the crack tip and welded the cracking region again, which had more favorable repairing effects than stophole and CFRP reinforcement. In the current experiment, fatigue life of specimen by re-welding, hammering and polishing was 7.1 times that of stophole specimen and 3.3 times that of CFRP specimen.

\section{Acknowledgements}

The authors appreciate the support of The National Natural Science Fund (No.51678215 and No.51678216) and the Fundamental Research Funds for the Central Universities (Grant 2018B50314). 